\title{
Application of Intrafascial Neurovascular Bundle Spare Technique in Radical Cystectomy
}

\author{
Tiejun Pan, Yu Zhou, Guoqiu Shen, Handong Wen, Weihong Qian \\ Department of Urology, Wuhan General Hospital, Guangzhou Command, Wuhan, China \\ Email: mnwkptj@yahoo.com.cn
}

Received May 20, 2013; revised June 22, 2013; accepted June 30, 2013

Copyright (C) 2013 Tiejun Pan et al. This is an open access article distributed under the Creative Commons Attribution License, which permits unrestricted use, distribution, and reproduction in any medium, provided the original work is properly cited.

\begin{abstract}
Objective: To investigate the significance of intrafascial neurovascular bundle spare technique in radical cystectomy. Methods: Between March 2010 and December 2011, a total of 26 bladder cancer patients were treated with radical cystectomy, and intrafascial neurovascular bundle spare technique was applied in all these patients. Mean age of 26 patients was 56.1 y (45 - 66). Among 26 patients, 21 cases were in stage T2, 5 cases were in stage T3. All patients choose Orthotopic neobladder as urinary diversion manner. We use intrafascial neurovascular bundle spare technique, dissect between prostatic fascial and prostatic capsule, spare neurovascular bundle. Operating time, blood loss, complications, continence and sexual function 3 months after surgery were recorded. Results: In all patients, mean operating time was $328 \mathrm{~min}$, mean blood loss was $316 \mathrm{ml}$. Only 4 patients need transfusion during surgery. 1 case of urinary fistula was found after surgery, and spontaneously cured 10 days after surgery. 1 case of bowel obstruction was found, and was cured by conservative therapy. 4 cases of incontinence were found 3 months after surgery. 18 patients had a nomal erectile function 3 months after surgery. Conclusions: Intrafascial neurovascular bundle spare technique can safely and effectively reserve neurovascular bundle in radical cystectomy. Patients can reserve continence and erectile function by this technique.
\end{abstract}

Keywords: Radical Cystectomy; Neurovascular Bundle Spare; Intrafascial Technique

\section{Introduction}

Standard radical cystectomy should resect badder, prostate and seminal vesicle. For most candidates for radical cystectomy, we can reserve their neurovascular bundle to preserve their continence and erectile function. From March 2010 to December 2011, we have performed 26 cases of radical cystectomy with intrafascial technique to reserve their neurovascular bundle.

\section{Patients and Methods}

\subsection{Clinical Datas}

All 26 patients, male, mean age 56.1 y (45 - 66 y), 21 cases in T2 stage and 5 cases in T3 stage. All patients chose orthotopic neobladder as urinary diversion manner. Cystoscope was performed in all patients to rule out urethral invasion. No metastasis evidence was found by CT scan.

\subsection{Methods}

When aeroperitoneum was established, 5 Trocars were inserted into abdominal cavity. Then pelvic cavity lymphonectomy were performed in both sides. Lymphonectomy extent included internal iliac artery lymph nodes, external iliac vessel lymph nodes and obturator nerve lymph nodes. Peritoneum was cut open at Douglas' Pouch, Vas deferens and seminal vesicle dissociation was performed, and then Levator ani muscle fascia and prostatic fascia were dissected to the prostatic capsule at 2 o'clock. Dissociation was performed between prostatic capsule and prostatic fascia. Then the space among Denonviller fascia, neurovascular bundle and seminal vesicle was found. Dissociation along the seminal vesicle distally till the space between prostatic capsule and prostatic fascia. And dissociation along this space to the apex of prostate. Dissociation to the 12 o'clock of prostate at the apex of prostate. Dorsal vein complex were transfixed and dissected at the apex of prostate. Urethra was dissected at the apex of prostate. Bladder pedicle and prostatic pedicle were ligated by Hemlock clips and cut off. An $8 \mathrm{~cm}$ incision was made at middle of lower abdominal wall. And the specimen was taken out. $40 \mathrm{~cm}$ ileum was chosen to make a pouch. Both ureters were 
anastomosed to the new pouch and then the new pouch was anastomosed to the urethra. Operational time, blood loss, complications after surgery, continence and erectile function after surgery were recorded.

\section{Results}

There was no mortality during or after surgery. And no patient converted to open surgery during operation. All patients were preserved neurovascular bundle on both sides with intrafascial technique. Mean operating time was $328 \mathrm{~min}$ (265 - $430 \mathrm{~min}$ ), mean blood loss $316 \mathrm{ml}$ (180 - $900 \mathrm{ml}) .4$ patients need transfusion during operation. 1 case of urinary fistula was found after surgery and was natural cured on the 10th day after surgery. 1 case of intestinal obstruction was found after surgery, and was cure by conservative treatment. 2 cases of hydronephrosis were found after surgery, and were stable during follow up till one year. Continence and erectile function were evaluated 3 months after surgery. All patients can pass urine by themselves. 4 cases of incontinence were found during follow up. 18 patients had normal erectile function 3 months after surgery.

\section{Disscusion}

Radical cystectomy was standard treatment method for muscle invasive bladder cancer. Standard radical cystectomy should resect badder, prostate and seminal vesicle. Traditionally, surgeons did not preserve neurovascular bundle beside the prostate, so that patients' continence and erectile function were affected. For most radical cystectomy candidates, they did not have prostate cancer simultaneously, so most of their neurovascular bundles can be preserved in order to preserve better continence and erectile function. A lot of surgeons were dedicated to improve it [1-3].

Dr. Walsh first performed neurovascular bundle sparing radical prostatectomy in 1983. Neurovascular bundle sparing radical prostatectomy greatly improved patients' continence and erectile function after radical prostatectomy. Then Dr. Walsh [4] applied this technique in radical cystectomy, and also improved continence and erectile function after surgery. Neurovascular bundle located posterolaterally of apex of seminal vesicle, and laterally of prostatic capsule and Denonviller's fascia, deeply of Pelvic fascia. Neurovascular bundle extend laterally along the prostate from bladder neck and form prostate pedicle. It extends closely to urethral sphincter and crosses diaphragma urogenitale.

Most surgeons use interfascia technique to spare neuronvascular bundle. They dissociate between prostate fascia and pelvic fascia to preserve neurovascular bundle. Since neurovascular bundle just locates at this area, dissociation can cause bleeding and nerve damage. Stol- zenburg et al. first use intra fascia technique in radical prostatectomy to preserve neurovascular bundle in 2006. They dissociate between prostate fascia and prostate capsule, which can protect neurovascular bundle between prostate fascia and prostate capsule. The dissociation begins from 2 o'clock of the bottom of prostate, and then dissociates neurovascular bundle from prostatic capsule. So the operating instruments need not directly touch the neurovascular bundle, and the view will be very clear and nerve damage probability can be greatly reduced [5]. Many surgeons also use this technique in radical prostatectomy [6-9].

In our group, mean operating time was 328 min, mean blood loss $316 \mathrm{ml}$. No serious complications were found after surgery. $84.6 \%$ patients were continent 3 months after surgery. $69.2 \%$ patients had normal erectile function 3 months after surgery. It indicates intra fascia technique can efficiently preserve patients' continence and erectile function in radical cystectomy. But we still need more cases to identify tumor control and long term survival benefit of this technique.

\section{REFERENCES}

[1] M. F. Dall’Oglio, A. A. Antunes, A. Crippa, A. J. Nesrallah and M. Srougi, "Long-Term Outcomes of Radical Cystectomy with Preservation of Prostatic Capsule,” International Urology and Nephrology, Vol. 42, No. 4, 2010, pp. 951-957. doi:10.1007/s11255-010-9749-0

[2] T. Lin, J. Huang, J. Han, K. Xu, H. Huang, C. Jiang, et al. "Hybrid Laparoscopic Endoscopic Single-Site Surgery for Radical Cystoprostatectomy and Orthotopic Ileal Neobladder: An Initial Experience of 12 Cases,” Journal of Endourology, Vol. 25, No. 1, 2011, pp. 57-63. doi:10.1089/end.2010.0332

[3] M. S. El-Bahnasawy, Y. Osman, A. El-Hefnawy, A. Hafez, M. Abdel-Latif, A. Mosbah, et al. "Radical Cystectomy and Urinary Diversion in Women: Impact on Sexual Function," Scandinavian Journal of Urology and Nephrology, Vol. 45, No. 5, 2011, pp. 332-338. doi:10.3109/00365599.2011.585621

[4] P. C. Walsh, H. Lepor and J. C. Eggleston, "Radical Prostatectomy with Preservation of Sexual Function: Anatomical and Pathological Considerations,” Prostate, Vol. 4, No. 5, 1983, pp. 473-485. doi:10.1002/pros.2990040506

[5] J. U. Stolzenburg, R. Rabenalt, A. Tannapfel and E. N. Liatsikos, "Intrafascial Nerve-Sparing Endoscopic Extraperitoneal Radical Prostatectomy,” Urolgoy, Vol. 67, No. 1, 2006, pp. 17-21. doi:10.1016/j.urology.2005.09.052

[6] S. Cusumano, F. Annino, E. R. Selas, S. Hanna, T. Piechaud and R. Gaston, "Feasibility, Technique, and Principles of Tension- and Energy-Free Laparoscopic Radical Prostatectomy with Lateral Intrafascial Dissection of the Neurovascular Bundles with the Use of a High-Definition Optical Device,” Journal of Endourology, Vol. 22, No. 9, 2008, pp. 1981-1987. 
doi:10.1089/end.2008.9762

[7] G. D. Stewart, I. El-Mokadem, M. E. McLornan, J. U. Stolzenburg and S. A. McNeill, "Functional and Oncological Outcomes of Men under 60 Years of Age Having Endoscopic Surgery for Prostate Cancer Are Optimal Following Intrafascial Endoscopic Extraperitoneal Radical Prostatectomy,” The Surgeon, Vol. 9, No. 2, 2011, pp. 65-71. doi:10.1016/j.surge.2010.07.005

[8] F. Greco, M. R. Hoda, S. Wagner, O. Reichelt, A. Inferrera, C. Magno and P. Fornara, "Bilateral vs Unilateral Laparoscopic Intrafascial Nerve-Sparing Radical Prosta- tectomy: Evaluation of Surgical and Functional Outcomes in 457 Patients,” BJU International, Vol. 108, No. 4, 2011, pp. 583-587. doi:10.1111/j.1464-410X.2010.09836.X

[9] J. U. Stolzenburg, P. Kallidonis, M. Do, A. Dietel, T. Häfner, R. Rabenalt, et al. "A Comparison of Outcomes for Interfascial and Intrafascial Nerve-Sparing Radical Prostatectomy," Urology, Vol. 76, No. 3, 2010, pp. 743748. doi:10.1016/j.urology.2010.03.089 